\title{
Integrating Graphic Organizers in Lesson Packages and Its Effect to Students' Levels of Conceptual Understanding
}

\author{
Ranulfo Friolo Cala \\ Biology Unit, Philippine Science High School-Central Visayas Campus, Cebu, Philippines
}

\section{Email address:}

calanulnul@gmail.com

\section{To cite this article:}

Ranulfo Friolo Cala. Integrating Graphic Organizers in Lesson Packages and Its Effect to Students' Levels of Conceptual Understanding. International Journal of Secondary Education. Vol. 7, No. 4, 2019, pp. 89-100. doi: 10.11648/j.ijsedu.20190704.11

Received: July 25, 2019; Accepted: August 13, 2019; Published: October 10, 2019

\begin{abstract}
The study investigated the effect of graphic organizers on students' levels of conceptual understanding, and the effect of students' cognitive level on conceptual understanding. The control group $(n=40)$ received a conventional classroom instruction while the experimental group $(\mathrm{n}=38)$ received an innovative classroom instruction, using graphic organizers. A mixed-method research design was employed. Pre-test, post-test, and Lawson's Classroom Test of Scientific Reasoning were utilized to compare quantitative results within and between groups. Qualitative data were gathered using structured interview schedule to further corroborate the quantitative findings. In comparison, results show that the experimental group significantly outperformed control group based on post-test results: remembering $(\mathrm{p}=0.001)$, analysis $(\mathrm{p}=0.001)$ and thinking beyond $(\mathrm{p}=0.013)$, except for application $(\mathrm{p}=0.906)$ which is not statistically significant. Furthermore, the correlation results show that, overall, there are no strong and significant correlations between students' concrete operational and transitional cognitive levels, and levels of conceptual understanding in both pre-test and post-test results for control and experimental groups. Since students' cognitive levels have no significant effect in enhancing students' conceptual understanding, therefore, the outperformance of the experimental group was due to the use of graphic organizers integrated in lesson packages.
\end{abstract}

Keywords: Cognitive Levels, Graphic Organizers, Levels of Conceptual Understanding

\section{Introduction}

\subsection{Background}

Science education researches across the world have been putting an emphasis not only on the content but on the science processes as well for the students to fully understand science concepts [13].

In the Philippine setting, with the need to develop the $21^{\text {st }}$ century skills, such as effective communication, critical/creative problem solving, responsible steward of nature, innovative/inventive thinking, and informed decision making, among students as stipulated in the Department of Education (DepEd) K to 12 Science Curriculum Guide [35], schools are tasked and challenged to ensure students learn and acquire the $21^{\text {st }}$ century skills as indicators of students' scientific literacy.

In line with the implementation of $\mathrm{K}$ to 12 Curriculum was also the adoption of Spiral Progression Approach in Science Curriculum which adds a pressing issue in the educational system of the country. In the spiral progression, secondary science teachers would either teach science topics that are out of their expertise or devise a way to still teach their specialization through quarterly rotation. In this way, a teacher who specializes in Biology/Physics/Chemistry/ Earth Science has to move from one grade level to another in every quarter. However, it has been observed that teachers tend to cover all the lessons quickly before the end of a quarter, which compromised the quality of teaching and learning. This would eventually lead to low conceptual understanding and retention of students, which were apparently shown in the results of an international assessment: Trends in International Mathematics and Science Study (TIMSS) 2003. Based on TIMSS 2003 International Science Reports, Philippines has an average scale score of 377 in grade 8 Science, which was significantly lower than the international average of 474, placing Philippines as one of the four lowest-performing countries [23]. The identified reason of low performance of Philippine students was the lack in skills to comprehend and communicate the science concepts, which is comparable to lack of conceptual understanding [16]. Hence, providing proper 
classroom intervention, such as the use of graphic organizers, is vital in attaining the desired goals [22]. In fact, according to Uba Oteikwu, Onwuka \& Eniayekan [31], graphic organizers are fast becoming the widely acceptable instructional intervention in the field of education globally.

Unfortunately, amidst these several education research on the positive impacts on the use of graphic organizers, these visual representations are yet to be recognized, integrated, and used as teaching and learning intervention [31] into the teaching methods in Philippine schools. Since most research on graphic organizers were done internationally, it might as well conduct a parallel research in Philippine context to be more appreciated with its advantages, motivating and encouraging Filipino teachers to integrate graphic organizers in their lessons.

This study, therefore, was conducted to determine the effect of integrating graphic organizers in lesson packages on students' levels of conceptual understanding. The study also aimed to determine the effect of students' cognitive level on the levels of conceptual understanding. Moreover, the study specifically sought the answers to the following questions:

What are the students' cognitive levels in both experimental and control groups?

What are the students' initial and final levels of conceptual understanding in both experimental and control groups in cell division and Mendelian genetics?

Are there significant differences in students' initial and final levels of conceptual understanding within control group, within experimental group, and between experimental and control groups?

What is the effect of students' cognitive levels in enhancing conceptual understanding among the students in both experimental and control groups?

How does the use of graphic organizers assist students' levels of conceptual understanding?

\subsection{Literature Review}

The knowledge on how human brain processes information has been the basis in developing innovative teaching strategies and learning techniques [33]. One of those is the use of graphic organizers to improve students' conceptual understanding. There are several cognitive theories that support the use of graphic organizers in improving students' mind in processing information and increasing retention. The theories that serve as the foundation on the use of graphic organizers include: constructivism [12], schema theory, dual coding theory and cognitive load theory [33].

\subsubsection{Constructivism}

It states that students can achieve meaningful learning from meaningful experience [12]. This means that students do not directly transfer information from the external world into their mind; rather they create their own personal interpretations of the external environment based on individual experiences and interactions. In constructivism, the interaction between the students and the external world is critical because together, these two variables create knowledge [12].

In constructivism, it is assumed that the transfer of information can be facilitated by involvement in a meaningful experience [12]. Thus, the role of instruction in this theory is to teach students on how to construct knowledge independently, and to collaborate with others [8].

\subsubsection{Schema Theory}

This theory states that memory is composed of a network of schemas or knowledge structures that help in facilitating mental processes [33, 27]. Schema theory assumes that information does not carry meaning by itself; rather it only provides directions for students as to how they should get, organize and construct meaning from their acquired knowledge and connect it to the prior knowledge [1].

\subsubsection{Dual Coding Theory}

This theory explains that human cognition has two interrelated subsystems for processing information [6, 27]. One subsystem is specialized for processing nonverbal (or imagery) representations and the other one that is specialized for processing of language [6, 27]. The subsystem that processes nonverbal or imagery representations, stores images that termed as imagens, while the subsystem that processes linguistic information, stores linguistic information that termed as logogens [33]. According to Jessen, Heun, Erb, Granath, Klose, Papassotiropoulos \& Grodd [18], dual coded information has the advantage to easy retrieval and retaining of information because of the access of each subsystem to one another and the availability of two subsystems, verbal and visual, instead of one. The more these two subsystems are used by the students, the better they can think and recall information [32].

\subsubsection{Cognitive Load Theory}

Cognitive load refers to the amount of resources in mind that are important in processing information [33]. Cognitive load theory states that working memory can store only a limited amount of information and when its capacity to store information is reached, the information is likely to be lost and forgotten resulting to low retention [33].

\subsubsection{David Kolb's Experiential Learning Theory (Constructivism) and Graphic Organizers}

Experiential learning theory asserts that knowledge is created from the transformed learning experiences. Kolb's experiential learning theory has four stages to learn effectively. These stages include: concrete experience involvement, reflective observation and listening, constructing knowledge with an abstract conceptualization, and active experimentation with good decision making. All these stages will be addressed by the use of graphic organizer, making it a powerful teaching and learning tool. An example is when students are engaged in learning experiences, such as reading textbook, magazines, web sites, journal articles and magazines, watching video clips, doing laboratory experiments, etc, graphic organizers allow students to develop the skills of note-taking, reading comprehension, summarizing and vocabulary development, which will lead to 
better understanding of the concepts. In this manner, students learn to create new knowledge and concepts independently from the activity, experience and prior knowledge, and be able to communicate their constructed concepts to others. Students will eventually apply it to real-life situations. As Hailikari, Katajavuori \& Ylanne [17] have emphasized that in order to promote higher-order thinking, students must be able to make new information from linking prior knowledge and new knowledge, and apply it in real-life scenarios. This can be easily achieved using graphic organizers.

\subsubsection{Schema Theory and Graphic Organizers}

According to Dye [11], the graphic organizers are grounded on schema theory. When students learn new information, they must be able to retain the information for later use (prior knowledge). In other words, people can encode, store, and retrieve learned information [30]. Thus, the teacher's task is to make sure that students have retained their prior knowledge related to the concept and to provide a way to help students easily create connections between prior knowledge and new concepts or information. The use of graphic organizers is one way to make it easier for the students to create a link between new information and the existing knowledge [15]. Moreover, graphic organizers help students build the schema necessary in understanding new concepts [15]. If existing knowledge is activated, the built schema will be able to provide a framework to which new information can be attached and learning and comprehension will be improved [33].

\subsubsection{Dual Coding Theory and Graphic Organizers}

The dual coding theory has definite implications on the value and use of graphic organizers. Marzano, Pickering and Pollock [24] state that graphic organizers can improve the development of non-verbal representations in students and can, therefore, improve the development of that content. According to Wills \& Ellis [33], the use of graphic organizers allows students generate linguistic representations. As a visual and linguistic tool, graphic organizers help students process and store information as imagens and logogens, which will be retrieved in order to recall information and content thereby dual coding the information [33].

\subsubsection{Cognitive Load Theory and Graphic Organizers}

Visual learning tools such as graphic organizers can reduce the cognitive load because it simplifies complex concepts into an organized, clear and concise form and as a result, allow more of the working memory to attend to learning new material [33]. As a result, content can be addressed at more sophisticated and complex levels through the use of graphic organizers [33].

\section{Materials and Methods}

\subsection{Research Design}

This study employed a developmental mixed-method, concurrent nested research design using pre-test, post-test,
Lawson's Classroom Test of Scientific Reasoning (LCTSR), structured interview schedule. The implementation of the study involved the developed learning packages integrating graphic organizers throughout the process of teaching and learning. Quantitative data were collected through administering pre-test and the test of scientific reasoning prior to the start of the lesson and post-test at the end of the whole unit. Qualitative data were collected through structured interviews. For the quantitative method, a control group was used to determine the effect of using graphic organizer on students' levels of conceptual understanding. There were two intact groups of Grade 8 students. One group was selected as the experimental group, while the other as the control group. Prior and after the use of graphic organizers, students from both the experimental and control groups were given the same set of test questions. For the qualitative method, the experimental group was interviewed to further determine the respondents' perceptions on the use of graphic organizers.

\subsection{Research Environment}

This study was conducted in a private catholic school, which is a PAASCU (Philippine Association of Accredited Schools, Colleges and Universities) - accredited school. The school follows the spiral progression approach and has four junior high school science teachers, who are specialized in teaching Biology, Chemistry, Physics and Earth Science, respectively. Junior high school science teachers follow quarterly rotations, teaching respective specialized subject. The study was implemented among Grade 8 students with only one biology teacher. All science classes have the time allotment of 275 minutes per week (55 minutes per session).

\subsection{Research Participants}

The school has a total number of 156 Grade 8 students (48 male and 108 female students) that were divided into four sections with 38-40 students per section. Two of the four sections were chosen as the participants of the study using nonrandom assignment (intact groups). One section was assigned as the control group (CG) with 40 students and the other as the experimental group (EG) with 38 students. These two groups were taken as the research participants.

Students from the two groups, control and experimental groups, took part in pre- and post-test and in answering Lawson's Classroom Test of Scientific Reasoning (LCTSR). Students from the experimental group answered a structured interview to determine the realizations in the implementation on the use of graphic organizers in the teaching and learning process.

\subsection{Research Instruments}

The research instruments used were pre-test, post-test, Lawson's Classroom Test of Scientific Reasoning (LCTSR), and structured interview schedule.

Pre-test/Post-test. The pre-test/post-test was an 8-item test consisting of 6 multiple-choice items, with four options for each item and 2 open-ended items. Each multiple-choice question is 
worth 1 point, while each open-ended question is worth 2 points. The pre-test and post-test were used to assess students' initial and final levels of conceptual understanding on Cell Division and Mendelian Genetics. The data from the pre- and post-test were used to determine if there were significant differences between the experimental and the control groups. The classification of students' levels of conceptual understanding were adapted from Austin Independent School District (AISD) REACH [2]. Level 1 (Remembering) required students to recall facts or information that needs the use of simple skills or abilities. Level 2 (Application of Knowledge) required students to make use of information, organize information that need two or more thought processes. Level 3 (Analysis) required a more complex and abstract cognitive demands. In this level, students could break a situation or problem into component parts that need strategic thinking, planning and using of evidence. Level 4 (Thinking Beyond) required students to create or devise something new based on the application of information.

Lawson's Classroom Test of Scientific Reasoning (LCTSR). The 2000-revised, multiple-choice edition of the LCTSR was used. The LCTSR consists of 12 scenarios, in which each scenario is succeeded by two questions that assess students' cognitive level [26]. It was administered to students to assess and measure cognitive level and fundamental reasoning [4].
To be considered correct, the students have to choose the correct answer and the explanation to the answer. LCTSR has the maximum score of 13 points with paired scoring. Items 1 to 22 are paired items, having a total of 11 points. Items 23 and 24 were scored independently, having a score of 2 points [34]. Total scores of students below $25 \%$ on the LCTSR were classified as concrete operational (using empirical-deductive thinking) cognitive level, scores between $25 \%$ and $58 \%$ were classified as transitional cognitive level, and scores above $58 \%$ were classified as formal operational (using hypothetical-deductive thinking) cognitive level [20, 26].

Interview Schedule. After all classroom instruction, students in the experimental group were asked to answer open-ended questions to determine on how their levels of conceptual understanding was assisted through the use of graphic organizers. The questions were used to assess students' perception on the use of graphic organizers [14].

\subsection{Research Procedures}

The research was divided into three stages: preintervention stage, intervention stage, and post-intervention stage (Figure 1). Each stage served as guide for the researcher in the whole process of research.

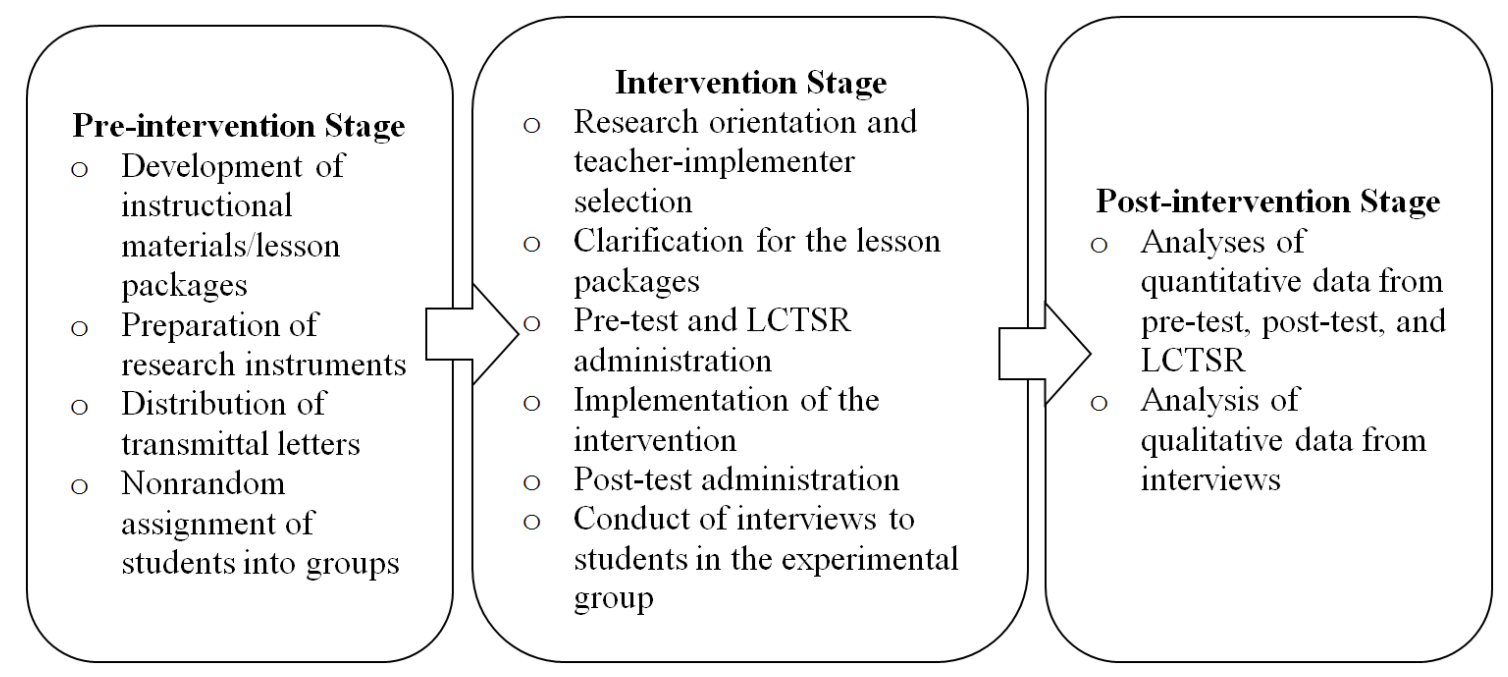

Figure 1. Research schematic diagram for data gathering.

To answer the first research sub-problem, (a) What are the students' cognitive levels in both experimental and control groups?, the results gathered from LCTSR were classified as to the corresponding cognitive levels: concrete operational, transitional, and formal operational.

To answer the second research sub-problems, (b) What are the students' initial and final levels of conceptual understanding in both experimental and control groups in cell division and Mendelian genetics?, the results gathered from both the pre-test and post-test were classified as to the corresponding level of conceptual understanding: remembering, application of knowledge, analysis, and thinking beyond.

To answer the third research sub-problems, (c) Are there significant differences in students' initial and final levels of conceptual understanding within experimental and control groups, and between experimental and control groups?, the means within the experimental group and the control group and the means between the experimental and control groups were obtained from pre-test and post-test results. Descriptive statistics was used to obtain the means within the experimental and control groups. T-test was used to compare the obtained means within the experimental group and control group, and between the experimental and control groups to identify if they were significantly different in terms of the results.

To answer the fourth sub-problem, (d) What is the effect of students' cognitive levels in enhancing the conceptual understanding among the students in both experimental and control groups?, the relationship between the results gathered 
from pre-test and post-test (per level of conceptual understanding) and students' cognitive levels from LCTSR results were determined. Pearson's correlation test was used to measure the degree of association between the variables: levels of conceptual understanding and cognitive levels.
To answer the fifth sub-problem, (e) How does the use of graphic organizers assist students' levels of conceptual understanding?, the data gathered from the interviews were summarized per question. Thematic analysis was used for easy interpretation of data. Data were coded by the researcher.

\section{Results}

\subsection{Students' Levels of Cognition}

Table 1. Cognitive levels of students from LCTSR

\begin{tabular}{|c|c|c|c|c|}
\hline \multirow{2}{*}{ Cognitive Level } & \multicolumn{2}{|c|}{ Control Group $(\mathrm{N}=40)$} & \multicolumn{2}{|c|}{ Experimental Group $(\mathbf{N}=37)$} \\
\hline & Frequency & Percent (\%) & Frequency & Percent (\%) \\
\hline Concrete Operational & 20 & 50.00 & 25 & 67.57 \\
\hline Transitional & 20 & 50.00 & 12 & 32.43 \\
\hline Formal Operational & 0 & 0.00 & 0 & 0.00 \\
\hline
\end{tabular}

Note: Concrete operational ( 2 points and below), transitional (3-8 points) and formal operational ( 9 points and above).

The data indicated that in both groups, students' cognitions were in concrete operational and transitional cognitive levels. In the control group, twenty out of forty students, representing $50 \%$ of the control group, were in concrete operational cognitive level, so as with the transitional level $(50 \%)$, and none $(0 \%)$ in the formal operational cognitive level. On the other hand, in the experimental group, twentyfive out of thirty-seven students, representing $67.57 \%$ of the experimental group, were in concrete operational cognitive level, while twelve students that comprised $32.43 \%$ of the group were in transitional cognitive level. Similarly, with control group, none $(0 \%)$ belong to formal operational cognitive level.

\subsection{Students' Levels of Conceptual Understanding}

The pre- and post-test questions were classified into conceptual understanding levels that include: Remembering, Application, Analysis and Thinking Beyond. Students' conceptual understanding levels were then identified as to the items or questions where they answered correctly. The tables below show the number of points aggregated per level in each topic: cell division and Mendelian genetics during the pre-test (Tables 2 and 3) and post-test (Tables 4 and 5) by both the control and experimental groups, with their corresponding percentages. Percentages in the pre-test were computed using the following total number of points: in control group, each level: Remembering, Application and Analysis, had a total of 39 points, while Thinking Beyond had 78 points. In experimental group, each level: Remembering, Application and Analysis, had a total of 38 points, while Thinking Beyond had 76 points.

In the post-test, percentages were also computed using the following total number of points per level: in control group, each level: Remembering, Application and Analysis, had a total of 39 points, while Thinking Beyond had 78 points. In experimental group, each level: Remembering, Application and Analysis, had a total of 35 points, while Thinking Beyond had 70 points.

Table 2. Initial conceptual understanding levels of students.

\begin{tabular}{|c|c|c|c|c|}
\hline \multirow{3}{*}{ Conceptual Understanding Level } & \multicolumn{4}{|c|}{ Pre-Test: Control Group ( $\mathbf{N}=39)$} \\
\hline & \multicolumn{2}{|c|}{ Cell Division } & \multicolumn{2}{|c|}{ Mendelian Genetics } \\
\hline & Points & Percent (\%) & Points & Percent (\%) \\
\hline Remembering & 20 & 51.28 & 14 & 35.90 \\
\hline Application & 5 & 12.82 & 12 & 30.77 \\
\hline Analysis & 22 & 56.41 & 9 & 23.08 \\
\hline Thinking Beyond & 0 & 0.00 & 0 & 0.00 \\
\hline
\end{tabular}

Table 3. Initial conceptual understanding levels of students.

\begin{tabular}{|c|c|c|c|c|}
\hline \multirow{3}{*}{ Conceptual Understanding Level } & \multicolumn{4}{|c|}{ Pre-Test: Experimental Group $(\mathbf{N}=\mathbf{3 8})$} \\
\hline & \multicolumn{2}{|c|}{ Cell Division } & \multicolumn{2}{|c|}{ Mendelian Genetics } \\
\hline & Points & Percent (\%) & Points & Percent (\%) \\
\hline Remembering & 17 & 44.74 & 15 & 39.47 \\
\hline Application & 7 & 18.42 & 18 & 47.37 \\
\hline Analysis & 13 & 34.21 & 17 & 44.74 \\
\hline Thinking Beyond & 0 & 0.00 & 0 & 0.00 \\
\hline
\end{tabular}


Table 4. Final conceptual understanding levels of students.

\begin{tabular}{lllll}
\hline \multirow{3}{*}{ Conceptual Understanding Level } & \multicolumn{3}{l}{ Post-Test: Control Group (N=39) } & Mendelian Genetics \\
\cline { 2 - 5 } & Cell Division & & Points & Percent (\%) \\
\cline { 2 - 5 } & Points & Percent (\%) & 18 & 46.15 \\
\hline Remembering & 29 & 74.36 & 25 & 64.10 \\
Application & 17 & 43.59 & 17 & 43.59 \\
Analysis & 14 & 35.90 & 8 & 10.26 \\
Thinking Beyond & 35 & 44.87 & 17 & \\
\hline
\end{tabular}

Table 5. Final conceptual understanding levels of students.

\begin{tabular}{lllll}
\hline \multirow{3}{*}{ Conceptual Understanding Level } & \multicolumn{3}{l}{ Post-Test: Experimental Group $(\mathbf{N}=\mathbf{3 5})$} & Mendelian Genetics \\
\cline { 2 - 5 } & Cell Division & & Points & Percent (\%) \\
\cline { 2 - 5 } & Points & Percent (\%) & 27 & 77.14 \\
\hline Remembering & 32 & 91.43 & 22 & 62.86 \\
Application & 15 & 42.86 & 25 & 71.43 \\
Analysis & 23 & 65.71 & 20 & 57.14 \\
Thinking Beyond & 43 & 61.43 & & \\
\hline
\end{tabular}

Among the students in the control group (Table 2), the level of conceptual understanding with the highest percentage for the topic cell division was Analysis with $56.41 \%$. The second highest was Remembering with $51.28 \%$ and Application as the level of conceptual understanding with the lowest percentage of $12.82 \%$. On the topic, Mendelian genetics, Remembering had the highest percentage with $35.90 \%$, followed by Application with $30.77 \%$ and Analysis with the lowest percentage of $23.08 \%$. In the experimental group (Table 3), the level of conceptual understanding with the highest percentage for the topic cell division was Remembering with $44.74 \%$. The second highest was Analysis with $34.21 \%$ and Application as the level of conceptual understanding with the lowest percentage of $18.42 \%$. On the topic, Mendelian genetics, Application had the highest percentage with $47.37 \%$, followed by Analysis with $44.74 \%$ and Remembering with the lowest percentage of $39.47 \%$.

Prior to the conduct of post-test, the two groups were given and engaged in different classroom instructional settings. Students in the control group were exposed to conventional classroom instruction, while students in the experimental group were exposed to innovative classroom instruction with the use of teaching-learning intervention the use of graphic organizers.

In the control group (Table 4), the level of conceptual understanding with the highest percentage for the topic cell division was Remembering with $74.36 \%$. The second highest was Thinking Beyond with $44.87 \%$, followed by Application with $43.59 \%$ and Analysis as the level of conceptual understanding with the lowest percentage of $35.90 \%$. On the topic, Mendelian genetics, Application had the highest percentage with $64.10 \%$, followed by Remembering with $46.15 \%$ and Analysis with $43.59 \%$. Thinking Beyond was the lowest with a percentage of $10.26 \%$. In the experimental group (Table 5), the level of conceptual understanding with the highest percentage for the topic cell division was Remembering with $91.43 \%$. The second highest was Analysis with $65.71 \%$, Thinking Beyond with $61.43 \%$ and Application as the level of conceptual understanding with the lowest percentage of $42.86 \%$. On the topic, Mendelian genetics, Remembering was also the level with the highest percentage of $77.14 \%$, followed by Analysis with $71.43 \%$, Application with $62.86 \%$ and Thinking Beyond with the lowest percentage of $57.14 \%$.

\subsection{Students' Levels of Conceptual Understanding Comparison}

Results of pre-test and post-test of control and experimental groups were compared within each group and between the two groups to determine how significant were the learning gains in the students. Descriptive statistics including means and standard deviations were used to examine the research questions. The mean showed the central tendency for each level, while the standard deviations provided an available explanation to potential distribution variations [19]. The data were analyzed using t-test to determine how statistically significant were the differences between two means, expressed as $p$-values for each level [22]. Statistically significant differences were determined based on an alpha level of 0.05 or less.

Table 6 and Table 7 show the results between pre-test and post-test results per conceptual understanding level within each group. These tables include the results of descriptive statistics including the mean and standard deviation, and $t$ test as $p$-value for each conceptual understanding level. Table 8 presents the comparison between control and experimental groups in pre-test and post-test results per level of conceptual understanding.

Table 6. Results of pre-test and post-test conceptual understanding levels.

\begin{tabular}{|c|c|c|c|c|c|}
\hline \multirow{3}{*}{ Conceptual Understanding Level } & \multicolumn{5}{|c|}{ Control Group } \\
\hline & \multicolumn{2}{|c|}{ Pre-test } & \multicolumn{2}{|c|}{ Post-test } & \multirow{2}{*}{$p$-value } \\
\hline & Mean & Std. Deviation & Mean & Std. Deviation & \\
\hline Remembering & 0.87 & 0.61 & 1.21 & 0.57 & $0.015 *$ \\
\hline Application & 0.44 & 0.60 & 1.08 & 0.70 & $0.000 *$ \\
\hline
\end{tabular}




\begin{tabular}{|c|c|c|c|c|c|}
\hline \multirow{3}{*}{ Conceptual Understanding Level } & \multicolumn{5}{|c|}{ Control Group } \\
\hline & \multicolumn{2}{|c|}{ Pre-test } & \multicolumn{2}{|c|}{ Post-test } & \multirow{2}{*}{$p$-value } \\
\hline & Mean & Std. Deviation & Mean & Std. Deviation & \\
\hline Analysis & 0.79 & 0.66 & 0.79 & 0.70 & 1.000 \\
\hline Thinking Beyond & 0.00 & 0.00 & 1.10 & 1.17 & $0.000^{*}$ \\
\hline
\end{tabular}

* Significant difference at the 0.05 level or less.

Table 7. Results of pre-test and post-test conceptual understanding levels.

\begin{tabular}{llllll}
\hline & \multicolumn{2}{l}{ Experimental Group } & & & \\
\cline { 2 - 5 } Conceptual Understanding Level & Pre-test & & Post-test & & Std. Deviation \\
\cline { 2 - 5 } & Mean & 0.72 & 1.69 & 0.58 & $0.000^{*}$ \\
\hline Remembering & 0.84 & 0.67 & 1.06 & 0.73 & $0.017^{*}$ \\
Application & 0.66 & 0.66 & 1.37 & 0.77 & $0.001^{*}$ \\
Analysis & 0.79 & 0.00 & 1.80 & 1.18 & $0.000^{*}$ \\
Thinking Beyond & 0.00 & & & & \\
\hline
\end{tabular}

* Significant difference at the 0.05 level.

Table 8. Comparison of conceptual understanding levels.

\begin{tabular}{lllllll}
\hline \multirow{2}{*}{ Conceptual Understanding Level } & Pre-Test & \multicolumn{3}{c}{ Post-Test } \\
\cline { 2 - 7 } & CG (Mean) & EG (Mean) & p-value & CG (Mean) & EG (Mean) & $\boldsymbol{p}$-value \\
\hline Remembering & 0.87 & 0.84 & 0.846 & 1.21 & 1.69 & $0.001^{*}$ \\
Application & 0.44 & 0.66 & 0.129 & 1.08 & 1.06 & 0.906 \\
Analysis & 0.79 & 0.79 & 0.971 & 0.79 & 1.37 & $0.001^{*}$ \\
Thinking Beyond & 0.00 & 0.00 & -- & 1.10 & 1.80 & $0.013^{*}$ \\
\hline
\end{tabular}

* Significant difference at the 0.05 level.

Control group was given a conventional classroom instruction different from the experimental group. Students in the group were not taught and exposed on the use of graphic organizers as a teaching-learning intervention. Experimental group was given an innovative or student-centered classroom instruction. Students in the group were taught and exposed on the use of graphic organizers as the teaching-learning intervention in every part of the lesson packages.

In the control group (Table 6), based on the criterion: significant difference at the 0.05 level or less, the mean differences were considered to be extremely statistically significant at the levels of Remembering, Application and Thinking Beyond with the $p$-values of $0.015,0.000$ and 0.000 respectively. However, the level of Analysis was not statistically significant with a $p$-value of 1.000 .

In the experimental group (Table 7), by conventional criterion which is significant difference at the 0.05 level or less, the mean differences were considered to be extremely statistically significant at all levels of conceptual understanding: Remembering, Application, Analysis and Thinking Beyond with the $p$-values of $0.000,0.017,0.001$ and 0.000 respectively.

Following the conventional criterion which is significant difference at the 0.05 level or less, the mean differences between the control and experimental groups were considered to be not statistically significant in the pre-test. All levels of conceptual understanding were shown to be no significant difference: Remembering, Application, Analysis and Thinking Beyond with the $p$-values of $0.846,0.129$, and 0.971 respectively (Table 8 ).

On the contrary, the mean scores between control and experimental groups in the post-test showed significant difference at the level of Remembering, Analysis and Thinking Beyond with the $p$-values of $0.001,0.001$ and 0.013 respectively (Table 8). However, at the level of Application, the result showed no significant difference between the mean scores of the two groups. It had the $p$-value of 0.906 .

\subsection{Students' Levels of Cognition and Levels of Conceptual Understanding Correlations}

Results of pre-test and post-test in both the control and experimental groups were correlated to their cognitive levels as identified using the Lawson's Classroom Test of Scientific Reasoning (LCTSR). Correlation was done per level of conceptual understanding and cognitive level. The data were analyzed using Pearson's correlation test to measure the strength of statistical relationship or association between two variables: cognitive levels and levels of conceptual understanding. Moreover, $p$-values were also determined to find out how statistically significant were the correlations. Statistically significant correlations were determined based on an alpha level of 0.05 or less.

Table 9 shows the correlations ( $r$-values) between cognitive levels and levels conceptual understanding in both control and experimental groups based from the results of the pre-test. Table 10 shows the correlations $(r$ values) between cognitive and conceptual understanding levels in both groups based from the post-test results. 
Table 9. Correlation (r) between cognitive levels and initial conceptual understanding levels.

\begin{tabular}{|c|c|c|c|c|c|c|c|c|}
\hline \multirow{4}{*}{$\begin{array}{l}\text { Conceptual Understanding Level } \\
\text { (Pre-test) }\end{array}$} & \multicolumn{8}{|c|}{ Cognitive Level } \\
\hline & \multicolumn{4}{|c|}{ Concrete Operational } & \multicolumn{4}{|c|}{ Transitional } \\
\hline & \multicolumn{2}{|c|}{ CG } & \multicolumn{2}{|l|}{ EG } & \multicolumn{2}{|c|}{ CG } & \multicolumn{2}{|l|}{ EG } \\
\hline & $r$-value & $p$-value & $r$-value & $p$-value & $r$-value & $p$-value & $r$-value & $p$-value \\
\hline Remembering & 0.242 & 0.303 & 0.063 & 0.746 & 0.162 & 0.508 & 0.000 & 1.000 \\
\hline Application & 0.181 & 0.445 & 0.042 & 0.841 & 0.180 & 0.461 & 0.156 & 0.628 \\
\hline Analysis & 0.021 & 0.931 & -0.043 & 0.838 & 0.456 & $0.050^{*}$ & 0.168 & 0.601 \\
\hline Thinking Beyond & -- & -- & -- & -- & -- & -- & -- & -- \\
\hline
\end{tabular}

* Correlation is significant at the 0.05 level (2-tailed).

Table 10. Correlation (r) between cognitive levels and final conceptual understanding levels.

\begin{tabular}{|c|c|c|c|c|c|c|c|c|}
\hline \multirow{4}{*}{$\begin{array}{l}\text { Conceptual Understanding Level } \\
\text { (Post-test) }\end{array}$} & \multicolumn{8}{|c|}{ Cognitive Level } \\
\hline & \multicolumn{4}{|c|}{ Concrete Operational } & \multicolumn{4}{|c|}{ Transitional } \\
\hline & \multicolumn{2}{|c|}{ CG } & \multicolumn{2}{|l|}{ EG } & \multicolumn{2}{|c|}{ CG } & \multicolumn{2}{|l|}{ EG } \\
\hline & $r$-value & $p$-value & $r$-value & $p$-value & $r$-value & $p$-value & $r$-value & $p$-value \\
\hline Remembering & 0.161 & 0.511 & -0.400 & 0.058 & -0.101 & 0.671 & -0.019 & 0.953 \\
\hline Application & -0.086 & 0.727 & -0.152 & 0.490 & 0.225 & 0.341 & 0.309 & 0.328 \\
\hline Analysis & 0.237 & 0.329 & -0.187 & 0.394 & 0.089 & 0.710 & -0.124 & 0.701 \\
\hline Thinking Beyond & -0.262 & 0.278 & 0.166 & 0.450 & 0.389 & 0.082 & 0.086 & 0.790 \\
\hline
\end{tabular}

Pearson's correlation test states that $r$ varies from -1 to +1 . The larger the $r$-value the stronger the correlation and vice versa. Rumsey [29] specifically interpreted correlation coefficient $r$ into no relationship/negligible (0.00-0.20), weak (0.30-0.40), moderate $(0.50-0.60)$, strong $(0.70-0.90)$ and perfect relationship (1.00).

Table 9 shows that in both groups for concrete operational cognitive level and initial levels of conceptual understanding, the correlation values range from -0.043 to 0.242 while in transitional cognitive level, the correlation values range from 0.000 to 0.456 . Moreover, Table 9 showed that each initial conceptual understanding level had no significant correlation to each cognitive level. The $p$-values between each initial level of conceptual understanding and concrete operational cognitive level range from 0.303 to 0.931 . In transitional cognitive level, the $p$-values range from 0.050 to 1.000 . Based on the criterion of significant correlation, the $p$-value between transitional cognitive level and analysis level in the control group (0.050) was considered statistically significant but showed a weak correlation/relationship between the two variables.

Table 10 shows that in both groups for concrete operational cognitive level and final levels of conceptual understanding, the correlation values range from -0.400 to 0.237. In transitional cognitive level, the correlation values range from -0.124 to 0.389 . Furthermore, Table 10 showed that each final conceptual understanding level had no significant correlation to each cognitive level. The $p$-values between each final level of conceptual understanding and concrete operational cognitive level range from 0.058 to 0.727. In transitional cognitive level, the $p$-values range from 0.082 to 0.953 . Correlation can only be considered statistically significant when at the level of 0.05 or less.

\subsection{Students' Perceptions on the Use of Graphic Organizers}

During the course of the interview with 34 participants from the experimental group, they were asked to give and express their perceptions on the use of graphic organizers. Since a structured interview was employed, responses of the students in succeeding pages were all verbatim responses.

All students (100\%) affirmed that they were assisted, using graphic organizers, to improve their levels conceptual understanding. Students' responses underwent thematic analysis and came up with three themes. Themes were arranged from the most to the least frequency a theme was mentioned in students' responses.

Students were asked on their perception on the use of graphic organizer activities in classroom instruction. Their responses had the following themes (Table 11).

Table 11. Students' perceptions on the use of graphic organizers.

\begin{tabular}{lll}
\hline Themes & Frequency & Percent (\%) \\
\hline Graphic organizers help students understand scientific concepts easily. & 29 & 85.30 \\
Graphic organizers provide fun and develop students' creativity. & 3 & 8.82 \\
Graphic organizers provide information of a concept. & 2 & 5.88 \\
\hline
\end{tabular}

Among the three themes, the theme: Graphic organizers help students understand scientific concepts easily, has the highest frequency in students' responses. It comprises $85.30 \%$ of the entire experimental group (Table 11 ).

Student 4: "I really like graphic organizers because with the help of it, I can memorize the concepts in easy way and no need for me to memorize long texts."

Student 9: "It makes the topic more understandable and you can take more information."

Student 12: "It makes it easier to study and understand. It 
helps me understand the lesson because the meaning of the description is direct to the point."

Student 27: "They help me understand more about the topic easier than memorizing the functions word by word. Instead graphic organizers help me shorten ideas to be more specific of the topic."

Student 29: "I like graphic organizer very much because it helps me understand the lesson. It has given me an idea of the whole lesson."

Students' responses showed that they recognized the importance of graphic organizers as tools to deepen and improve their understanding of scientific concepts. This only showed that graphic organizers have the potential and are effective tools to enhance students' understanding of concepts. Similarly, in the study conducted by Condidorio [7] among grade 6 science class, he concluded that graphic organizers increased students' learning in content areas and students were able to gain a thorough scientific concepts. In addition, in a study by Lusk [21], graphic organizers allowed easier assimilation among students, which also allowed them to have greater understanding and comprehension of scientific concepts.

Other responses of the students included the following, which comprised the two other themes, Graphic organizers provide fun and develop students' creativity (8.82\%) and Graphic organizers provide information of a concept (5.88\%).

Student 15: "I like graphic organizers because it makes learning a lot more fun and creative."

Student 19: "I like them so much because they are easy to understand and it is creative."

Student 28: "These activities are some of favorite activities because I can put information and notes in an ordered way and organized while at the same time, it looks creative and fun to learn."

Student 23: "I like graphic organizer a lot because it has a main idea and details."

Student 30: "I like graphic organizer activities because for me, it feels so organized because I get confused when all the details are everywhere. With the help of graphic organizers, I get to understand the details more."

Student 29: "I like graphic organizer very much because it helps me understand the lesson. It has given me an idea of the whole lesson."

In relation to the result that graphic organizers help improve conceptual understanding (Table 11), students were also asked if their understanding on scientific concepts was really assisted by graphic organizers and how these were assisted.

There were $100 \%$ of the students, who responded that they were assisted by the use of graphic organizers to deeply understand scientific concepts. Their responses had the following themes:

A. Graphic organizers simplify complex scientific concepts.

Student 9: "Yes, by making it easier to understand topics that are hard."
Student 11: "Yes. It makes the lessons easier to understand. It makes me process the information presented faster than when it is presented word by word only. It organizes the ideas nicely and neatly."

Student 12: "Yes. It helps me well understanding the topics and the comparison between something."

B. Graphic organizers provide links or connect concepts.

Student 2: "Yes. By the way it presented the scientific concepts. Such as connecting to another concept relevant to it to let the readers understand it thoroughly and clearly."

Student 4: "Yes, because in science, there are sub-concepts so with the help of graphic organizers, the concept and terms can be subdivided properly."

Student 18: "Yes because it lets me see where it is linked."

C. Graphic organizers give summary of scientific concepts.

Student 29: "These graphic organizers did assist me in understanding scientific concepts discussed although one graphic organizer (the meiosis one where there was the Gap one, two, and etc.) made me confused. The graphic organizers summarize the lesson or like explain something for me."

Student 30: "Yes, because it collects and puts together all the details and stuff to be studied. It is not hard to study anymore."

Student 34: "Graphic organizers serve for me as a summary of the topic, and it helped me recall and refresh the topic discussed in the mind."

\section{Discussion}

\subsection{Students' Levels of Cognition}

The data in Table 1 implied that majority of the students in experimental group can think logically but have the difficulty in solving problems without appropriate hands-on activities or when outside concrete contexts as compared to the control group. These concrete reasoners struggle when dealing with abstract concepts and hypothetical situations [25]. Whereas, in transitional level, there were more students in the control group who can successfully use appropriate logic in solving problems, and in demonstrating abstract concepts and hypothetical tasks in most contexts [25] as compared to the experimental group.

\subsection{Students' Levels of Conceptual Understanding}

In Tables 2 and 3, results revealed that apparently the initial levels of conceptual understanding of students in both groups, on the topics of cell division and Mendelian genetics, were only at the level of Remembering, Application and Analysis during the conduct of pre-test prior to classroom instruction. In Remembering, students could only recall ideas such as facts or information, concepts and theories that needs the use of simple skills or abilities [5]. In the level of Application, students who have this level of learning could use abstract concepts and ideas in concrete situations. They could make use of information, organize information that 
need two or more thought processes [5]. In Analysis level of conceptual understanding, students could already break ideas, problems or situations into component parts and logical premises that require strategic thinking, planning and using of evidences [5]. Moreover, students from the two groups did not have the ability to create or develop new ideas based from unrelated parts and concepts [5] as shown in the data with $0 \%$ in the level of Thinking Beyond for the topics: cell division and Mendelian genetics.

The results in Tables 4 and 5 indicated that the final levels of conceptual understanding of students were already at the four levels: Remembering, Application, Analysis and Thinking Beyond during the conduct of post-test after the implementation of classroom instruction. The results from both groups suggested that apart from students' ability to recall facts and concepts, use abstract concepts and ideas in concrete situations, and break ideas, problems or situations into component parts, they have learned and developed their ability to create or develop new ideas based from unrelated parts and concepts [5] as shown in the data on the level of Thinking Beyond.

Similarly, in the study conducted by D \& Rajan [10] among middle school students in the western part of Tamil Nadu, India, they administered the pre-test and post-test to determine students' level of proficiency. The pre-test results showed that both groups' comprehension skills were on the same level and mostly on the lower levels. In the post-test results, both groups showed improvements in their comprehension skills as compared to the pre-test results. In addition, the same results were obtained in the study of Piri Ardakani \& Lashkarian [28] among Iranian intermediate students, who also aimed to determine the effect of graphic organizers to students' comprehension skills.

\subsection{Students' Levels of Conceptual Understanding Comparison}

The results in Table 6 revealed that the mean scores between the pre-test and the post-test within the control group were statistically significant, except for Analysis. These results indicated that conventional classroom instruction, without the use of graphic organizers, were effective to some extent in improving conceptual understanding. The differences on the pre-test and post-test means showed that students scored better after direct instruction using conventional teaching methods. In some studies, conventional teaching methods could positively influence research skills, performance in examinations and various abilities of students [9].

The results in Table 7 revealed that the mean scores between the pre-test and the post-test within the experimental group were all statistically significant. The results indicated that innovative classroom instruction, integrating the use of graphic organizers as instructional intervention, were effective and useful to improve students' scientific understanding. The differences on the pre-test and post-test means showed that students scored better after exposing themselves and after utilizing graphic organizers. In fact, according to Condidorio [7], graphic organizers are effective tools to address students' various levels of comprehension by providing differentiated material where students can utilize their ideas to create new information. Moreover, graphic organizers are important tools that students can utilize to aid comprehension on complex topics and materials [22], particularly in science.

The results in Table 8 indicated that the higher increase of conceptual understanding in experimental group, as compared to the control group, was brought about using of graphic organizers in the teaching-learning process. Thus, the results suggested that the integration and utilization of graphic organizers was effective in improving students' conceptual understanding than the usual use of traditional and conventional teaching methods. Similarly, in the studies conducted by Condidorio [7] and Mann [22], they found out that graphic organizers facilitate a thorough understanding of scientific concepts. Further, graphic organizers taught students to become independent learners and become prepared in using their skills independently. Furthermore, graphic organizers guarantee students' understanding of concepts and achievement [31].

In the study of D \& Rajan [10], they found out that there were significant differences between pre- and post-test results within the experimental group and between the two groups. These findings helped them came up with a conclusion that graphic organizers were effective tools to improve students' comprehension skills. Another study was carried out by Uba et al. [31] among senior secondary students in Nigeria. The findings revealed that students in graphic-based schools (using graphic organizers in teaching) had low score in average and good performance but high score in high performance category, whereas students in nongraphic-based schools had high score in average and good performance category but very low score in high performance category. These findings made them conclude that the high comprehension level of the students in the graphic-based schools was due to the use of graphic organizers as tools in their learning process.

\subsection{Students' Levels of Cognition and Levels of Conceptual Understanding Correlations}

Based on the interpretation of correlations by Rumsey [29], results in Table 9 revealed that there were no correlation to weak correlations between students' concrete operational and transitional cognitive levels, and each initial level of conceptual understanding in the pre-test for both groups. Moreover, results revealed that students' cognitive levels had no strong and mostly no significant effect to students' initial levels of conceptual understanding of scientific concepts.

Results in Table 10 suggested that there were negligible to weak correlations between students' concrete operational and transitional cognitive levels, and each final level of conceptual understanding in the post-test for both groups. Furthermore, results revealed that students' cognitive levels had no strong and significant effect to students' final levels of conceptual understanding of scientific concepts. 
Overall, the results from Tables 9 and 10 suggested that students' level of cognition had no strong and significant relationship to their levels of conceptual understanding or how they developed conceptual understanding. This means that students' cognitive levels had no significant effect in enhancing students' conceptual understanding. Hence, the main reason of improved conceptual understanding was the teaching-learning intervention used by the teacher/facilitator. Both groups had improved their understanding, yet the experimental group had outperformed the control group. The preceding results showed that this improvement was due to the integration and utilization of graphic organizers, which the control group had not experienced.

\subsection{Students' Perceptions on the Use of Graphic Organizers}

Table 11 and students' responses revealed that students' understanding was assisted and improved through graphic organizers by simplifying the concepts discussed, providing connections and links between and among scientific concepts, and highlighting and summarizing important concepts necessary for better and deep understanding of the topics. This, in fact, is supported by the study of Ayverdi, Nakiboglu \& Oz Aydin [3], to which they concluded that students were able to comprehend and understand concepts with the aid of graphic organizers. In their study, they asserted that the former became possible because concepts were being simplified by graphic organizers through establishing relationships between and among essential concepts of a broad topic.

\section{Conclusions}

Based on the findings derived from this study, researcher concludes that the use of conventional teaching method improved levels of conceptual understanding of the students, however, the use of innovative or student-centered teaching method with the integration of graphic organizers in lesson packages was better than the conventional method in enhancing, improving and deepening students' understanding of scientific concepts. Moreover, the researcher concludes that graphic organizers were, therefore, useful and effective tools for teachers in simplifying and summarizing complex topics or concepts, and at the same time for students to organize concepts and learn independently.

On the relationship between students' cognitive levels and levels of conceptual understanding, the researcher concludes that there were no strong and significant correlations between the two variables. This means that students' cognitive level has no strong nor significant effect to students' improved levels of conceptual understanding. The observed improvement in students' understanding, particularly among the experimental group, was due to teaching-learning intervention which is the use of graphic organizers.

\section{Acknowledgements}

This thesis would not have been possible without the help of the Department of Science and Technology - Science Education Institute (DOST-SEI), for the scholarship grant through its Accelerated Science and Technology Human Resource Development Program - Capacity Building Program in Science and Mathematics Education (ASTHRDP - CBPSME).

\section{References}

[1] An, S. (2013). Schema Theory in Reading. Theory and Practice in Language Studies, 3 (1), 130-134.

[2] Austin Independent School District REACH. (2011). REACH Student Learning Objective (SLO) Manual. Retrieved from https://www.austinisd.org/sites/default/files/dept/reach/SLO_ Manual_2013-2014FinalRevisedJ_0.pdf

[3] Ayverdi, L., Nakiboglu, C., \& Oz Aydin, S. (2014). Usage of Graphic Organizers in Science and Technology Lessons. Procedia-Social and Behavioral Sciences, 116, 4264-4269.

[4] Bao, L., Cai, T., Koenig, K., Fang, K., Han, J., Wang, J.,... Wu, N. (2009). Supporting Online Material for Learning and Scientific Reasoning. Science, 323, 586-587.

[5] Cannon, H. M. \& Feinstein, A. H. (2005). Bloom Beyond Bloom: Using the Revised Taxonomy to Develop Experiential Learning Strategies. Development in Business Simulations and Experiential Learning, 32, 348-356.

[6] Clark, J. M., \& Paivio, A. (1991). Dual Coding Theory and Education. Educational Psychology Review, 3 (3), 149-210.

[7] Condidorio, K. (2010). The Usefulness of Graphic Organizers in Enhancing Science Learning. Education Masters. Paper 111

[8] Cunningham, D. J. (1991). Assessing constructions and constructing assessments: A dialogue. Educational Technology, 31 (5), 13-17.

[9] Dimitrios, B., Labros, S., Nikolaos, K., Maria, K. \& Athanasios, K. (2013). Traditional Teaching Methods vs. Teaching through the Application of Information and Communication Technologies in the Accounting Field: Quo Vadis? European Scientific Journal, 9 (28), 73-101.

[10] D, P. S., \& Rajan, P. (2013). Using Graphic Organizers to Improve Reading Comprehension Skills for the Middle School ESL Students. English Language Teaching, 6 (2), 155-170.

[11] Dye, G. A. (2000). Graphic Organizers to the Rescue! Teaching Exceptional Children, 32 (3), 72-76.

[12] Ertmer, P. A. \& Newby, T. J. (2013). Behaviorism, Cognitivism, Constructivism: Comparing Critical Features From an Instructional Design Perspective. Performance Improvement Quarterly, 26 (2), 43-71.

[13] Evagorou, M., Erduran, S., \& Mäntylä, T. (2015). The role of visual representations in scientific practices: from conceptual understanding and knowledge generation to 'seeing' how science works. International Journal of STEM Education, 2 (1), 1-13. 
[14] Goss, P. A. (2009). The influence of graphic organizers on students" ability to summarize and comprehend science content regarding the earth"s changing surface. 1-110. Retrieved March 13, 2018.

[15] Guastello, E., Beasley, T., \& Sinatra, R. C. (2000). Concept Mapping Effects on Science Content Comprehension of LowAchieving Inner-City Seventh Graders [Abstract]. Remedial and Special Education, 21 (6), 356-364.

[16] Gutierrez, R., \& Ikeda, H. (2009, November). Response pattern analysis on the burning candle experiment: TIMSSbased study. Paper presented at the Third International Conference on Science and Mathematics Education (CoSMEd) 2009 Penang, Malaysia.

[17] Hailikari, T., Katajavuori, N., \& Lindblom-Ylanne, S. (2008). The Relevance of Prior Knowledge in Learning and Instructional Design. American Journal of Pharmaceutical Education, 72 (5), 1-8.

[18] Jessen, F., Heun, R., Erb, M., Granath, D., Klose, U., Papassotiropoulos, A., \& Grodd, W. (2000). The Concreteness Effect: Evidence for Dual Coding and Context Availability. Brain and Language, 74 (1), 103-112.

[19] Johnson, D. R. (2011). A Quantitative Study of Teacher Perceptions of Professional Learning Communities' Context, Process, and Content. Seton Hall University Dissertations and Theses (ETDs). 15.

[20] Locaylocay, J. R. (2002). Changes in college students conceptions of chemical equilibrium. $\mathrm{PhD}$ thesis, University of the Philippines, Diliman, Quezon City 2002. Published as book: Centre for International Cooperation, Vrije Universiteit, Amsterdam, ISBN 90-9019266-2.

[21] Lusk, K. (2014). Teaching High School Students Scientific Concepts Using Graphic Organizers. Theses, Dissertations and Capstones. Paper 895.

[22] Mann, M. L. (2014). The Effectiveness of Graphic Organizers on the Comprehension of Social Studies Content by Students with Disabilities. Theses, Dissertations and Capstones. Paper 890.

[23] Martin, M. O., Mullis, I. V., Gonzalez, E. J., \& Chrostowski, S. J. (2004). TIMSS 2003 International Science Repor. Chestnut Hill, MA: TIMSS \& PIRLS International Study Center, Lynch School of Education, Boston College.
[24] Marzano, R. J., Pickering, D. J., \& Pollock, J. E. (2001) Classroom Instruction That Works: Research-Based Strategies for Increasing Student Achievement.

[25] Moore, J. C. (2012). Transitional to Formal Operational: Using Authentic Research Experiences to Get Non-Science Students to Think More Like Scientists. European J of Physics Education, 1-2.

[26] Moore, J. C., \& Rubbo, L. J. (2012). Scientific reasoning abilities of nonscience majors in physics-based courses. Physical Review Special Topics - Physics Education Research, 8 (1), 010106-1-010106-8.

[27] Owolabi, J., \& Adaramati, T. (2015). Effects of Graphic Organiser on Students' Achievement in Algebraic Word Problems. Journal of Education and Practice, 6 (5), 39-44.

[28] Piri Ardakani, M., \& Lashkarian, A. (2015). Using Mind Mapping Strategy to Improve Reading Comprehension Ability to Intermediate Iranian Student. Science Journal, 36 (3), 10771095 .

[29] Rumsey, D. J. (2016). Statistics for Dummies (2nd ed.). New York, United States: John Wiley \& Sons.

[30] Slavin, R. E. (1991). Synthesis of research on cooperative learning. Educational Leadership, 48, 71-82.

[31] Uba, E., Oteikwu, E. A., Onwuka, E., \& Eniayekan, E. A. (2017). A Research-Based Evidence of the Effect of Graphic Organizers on the Understanding of Prose Fiction in ESL Classroom. SAGE Open, 7 (2), 1-9.

[32] Wandberg, R., \& Rohwer, J. (2010). Teaching Health Education in Language Diverse Classrooms. Canada: Jones and Bartlett.

[33] Wills, S., \& Ellis, E. (2008). The Theoretical and Empirical Basis for Graphic Organizer Instruction. 1-21. Retrieved March 13, 2018.

[34] Xiao, Y., Han, J., Koenig K., Xiong, J., \& Bao, L. (2018). Multilevel Rasch modeling of two-tier multiple choice test: A case study using Lawson's classroom test of scientific reasoning. Physical Review Physics Education Research, 14 (2), 020104-1 - 020104-18.

[35] Department of Education (2016, August). K to 12 Science Curriculum Guide [PDF]. 